only 24 cases progressed to excision, 22 of the first group, and 2 of the second, a percentage of 8.5. In a later series (1927) of 190 cases, the percentage of excised eyes was reduced to 4.6. These results would seem to justify the authors' claim that radiation is the treatment of choice in such cases. The book is an important exposition of a relatively new and little known branch of ophthalmological therapeutics, and is valuable, not only because of the authoritative information which it contains, but also for the lack of bias in the opinions which it expresses.

\title{
CORRESPONDENCE
}

\section{A CASE OF FUNCTIONAL BLINDNESS}

\section{To the Editor of The British Journal of Ophthalmology.}

SIR,--I shall feel much obliged if you will kindly give some space in your valued journal to the following case which I am sure would be of great interest to the medical practitioner in general and the ophthalmologist in particular.

On April 6, 1928, when I was working in my consulting room, I got a telephone message to the effect that a young man soon after coming from the church got suddenly blind and that I should see him immediately. I asked his relatives to bring him to the office and within half an hour he was there.

$\mathrm{He}$ is a clerk, of healthy appearance, and 26 years of age.

Family history:-Father alive, aged 51 years. Mother died of heart failure when the patient was 2 years old. No brothers. One sister from stepmother, 14 years old and healthy.

Habits :-Fairly active, smokes 25 cigarettes a day, a teetotaller, eats meat in fair quantities and is fond of reading a lot particularly at night.

Physical examination:-The patient when he entered my room was brought by the aid of two individuals and was completely blind.

$\mathrm{He}$ had not even perception of light as he failed to appreciate a strong electric light which was in front of him. On examination nothing abnormal was found on inspecting the anterior parts of the eyes, and the fundus, as far as could be seen with the undilated pupil, was normal.

I put in half per cent. of atropine before making another examination and engaged him in conversation and found tremors of 
lips and of fingers. From his replies to questions he seemed a man of emotional nature. I made another darkroom examination and again failed to find anything abnormal there. I made up my mind as to diagnosis (i.e., functional blindness). To make sure, I called him again next morning and prescribed in the meantime a blue pill to be taken at night and followed up by mag. sulph. in the morning. He went back with his relatives to the chemist to get the medicine. On the way the young man had a violent sneeze and immediately recovered his sight. Next morning he entered my room unaided, which confirmed my diagnosis of functional blindness. To make matters doubly sure, I sent him to a well-known physician for examination. The physician did not find anything organically wrong with him except that he had a few bad teeth which required looking after. All his organs were sound and healthy. Urine, normal. Reflexes, exaggerated. I think, it would be well if I here quote the physician's own sentence. "He (the patient) has told me all his history and I conclude that he is a case of hysteria.

The treatment needs no special comment."

During my practice of 20 years, this is the first case of its kind that I have seen.

Yours truly,

S. P. SHROFF.

P.S.-Field of vision in both eyes slightly contracted concentrically. DELH .

April 13, 1928.

\section{THE TREATMENT OF HYPOPYON ULCER}

\section{To the Editor of The British Journal of Ophthalmology.}

SIR,-Since reading the various plans of treatment for hypopyon ulcer, I would like to state my method of dealing with such cases.

Following upon the introduction of the colloidal compounds of mercury and silver (Crookes), I have practically used no other remedies in the past eight to ten years. I practically never use cautery or carbolic acid. As soon as a case is recognised-and the earlier the better-it is admitted to hospital, if a poor patient, and treatment with colloidal mercury is started.

Now it is useless to instil it three or four times a day. What is 